to show the usual finfings such as scheme 1 and 2. Although there is no remarkable difference in size of the muscle fibers in the diaphragm, three types of muscle fibers respectively showing the blue, violet and reddish purple reactions are observed as well (Scheme 3).

The red muscle, such as m.adductor magnus, containing a large number of the red muscle fibers which show large size than in the white muscle reveals generally a different finding. In this case, the muscle fibers in large size stain reddish purple with iodine (Scheme 4 ).

The abdominal muscle consists of various types, and there are some differences among individual layer of the abdominal wall.

From the distribution of active phosphorylase in muscle fibers, the iodineblue fiber seems to be a pyramidal kinetic fiber and the iodine reddish fiber seems to be an extrapyramidal tonic fiber.

\title{
Histochemical Study on Ischemia of Skeletal Muscle Mainly on Changes of Glycolytic and Lipolytic Enzymes
}

\author{
Hitoshi Tanabe, M.D., Masanori Tomonaga, M.D., Osamu Wada, M.D. \\ and Masanori Uono, M.D. \\ (Director: Prof. Kiku Nakao, M.D.) \\ The Third Department of Internal Medicine, Faculty of Medicine, \\ University of Tokyo, Tokyo.
}

For the research on the neuromuscular disorder, several procedures have widely been employed, i.e. sciatic denervation, sympathetic ganglionectomy, disuse method and some drug administrations. However, the examination of the ischemic skeletal muscle is also considered to be available, though the simple ischemic condition is difficult to produce. It was therefore tried, in this paper, to improve a method for transient ischemia, and to study the morphological and histochemical changes of the skeletal muscles in ischemic state and subsequent recovery period.

Histochemical works on the ischemic muscles, previously attempted by Moor $^{2)}$, Zimmerman $^{(0)}$, Scully ${ }^{6)}$ and Stenger ${ }^{7)}$, have been concerned with glycogen, succinic dehydrogenase, alkaline phosphatase and lipid ${ }^{12}$. In this report, however, more kinds of enzymes and other substances were widely investigated.

\section{Materials and Methods}

Fifty-nine albino rats were traumatized by the unilateral application of 
tight tourniquets to the hindleg for 1,2 and $3 \mathrm{hr}$, followed by their release.

The technique was a modification of original method developed by Rosenthal ${ }^{\text {s) }}$ who produced the transient occlusion by tight rubber band of arteries and veins of both hindlegs of mice for $2 \mathrm{hr}$.

The animals were sacrificed by decapitation at $30 \mathrm{~min}, 1,3,6,12,24 \mathrm{hr}, 2,5$, 7 and 14 days' recovery time, and the examination of muscles of lower hindlegs was performed both on affected and normal side at the same time.

Histochemical procedures employed mainly were those for phosphorylase (Takeuchi), succinic dehydrogenase (Nachlas et al.), aldolase (Abe \& Shimizu), acid and alkaline phosphatase (Gomori), cholinesterase (Koelle), lipase (Gomori; Takeuchi et al.), PAS reaction, glycogen, and lipid, and the method for morphological examination (H-E, trichrome etc.) was also applied.

\section{Results}

\section{Morphological observation}

Short-term ischemia $(1 \mathrm{hr})$, followed by the recovery time, produced no consistent change in morphological observation. Moderate or long time (2 and $3 \mathrm{hr}$, in our series) ischemia caused, in recovery stage, various forms of focal degeneration, predominantly in the center of the transvers section of the lower hindleg. During ischemia and early recovery stage, congestion and edema were the main changes. However, in the recovery course, cell infiltration, capillary and connective tissue proliferation appeared. Many apparently normal and atrophic fibers were surrounded by proliferating sarcolemmal nuclei and connective tissue. There were many atrophic muscle fibers with central nuclei and frequent mitotic figures.

\section{Histochemical examination}

Phosphorylase activity showed marked decrease after 6 to $12 \mathrm{hr}$ recovery time and difference between red and white fiber was not maintained. In ischemic and earlier recovery period the activity was normal or rather intense.

Gradual decrease of aldolase activity was also observed within 7 days recovery. Changes of succinic dehydrogenase activity resembled to those of aldolase. However, irregular reaction in destructed mitochondria was observed at high power examination in early stage of recovery.

Ischemia not only affected the muscle fibers, but also the connective tissue, including capillaries. Increase of acid and alkaline phosphatase activity was demonstrated in capillary wall and connective tissue in accordance with their proliferation. Acid phosphatase was also found in atrophied or regenerative muscle fiber.

Slight decrease of cholinesterase activity was frequently observed in atrophied or swelling motor end-plate.

Lipase activity change was not clearly demonstrated, while muscle fiber lipide was affected by ischemia and droplets appeared in the fiber within 2 or 3 days of blood supply. A histochemical method for epinephrine-sensitive lipolytic activity was also investigated and slight decrease was observed in a stage of 
recovery, although there remained some problems requiring further study.

Slight reduction of glycogen was shown in 2 or 3 days recovery. After about 7 days, PAS-positive material could be demonstrated in raised amounts both in surviving normal fibers and in regenerated fibers.

\section{Discussion}

Characteristic changes of some enzymic activity were demonstrated. Among them, the decrease of dehydrogenase is probably due to the mitochondrial change, while the decrease of free movable sarcoplasmic enzyme may be concerned membrane. The phase of transient increase of phosphorylase, aldolase and succinic dehydrogenase was not clearly detected.

Increase of phosphatases is commonly known as a regenerative reaction of severe damage of some tissue, central nuclei of the atrophied muscle is likely due to the same mechanism.

Whereas experimental denervation caused a standard change in muscle, ischemia did not, since its effects depended upon its completeness and duration, and also upon the recovery time allowed.

Following this series, further study on chronic stage after ischemia is also attempted.

\section{Acknowledgment}

Authors' acknowledgment is due to Prof. K. Nakao for the valuable guidance and advices.

\section{References}

1) Beckett, E.B. : Rev. canad. Biol., $21: 391,1962$.

2) Moor, D.H. Ruska, H. and Copenhaven, W.M. : J. Biophys. Biochem. Cytol., 2 : 755, 1956.

3) Pearse, A.G.E. : Histochemistry, 2nd edition, Churchill, 1960. 4) Rizack, M.A.: J. Biol. Chem., $236: 657,1961$. 5) Rosenthal, S.M.: Pub. Health Rep., $57: 1923,1942 . \quad$ 6) Scully, R.E., Shannon, J.M. and Dickerin, G.R. : Am. J. Path, $39: 721,1961 . \quad 7)$ Stenger, R.J., Spiro, D., Scully, R.E. and Shannon, J.M. : Am. J. Path. $40: 1,1962 . \quad 8)$ Takeuchi, T.: J. Histochem. Cytochem. 3 : 153, 1955 ; ibid, $8: 277,1960 . \quad 9)$ Uono, M., Tanabe, H., Ueda, S. and Tomonaga, M. : Proc. Jap. Histochem. Ass. $1: 2$, 1961 . 10) Zimmerman, H. and Schleifer, D. : Acta Histochem.; $8: 221,1959$. 